\title{
Oscillation Theorems for Second-Order Nonlinear Neutral Delay Differential Equations
}

\author{
Tongxing $\mathrm{Li}^{1}$ and Yuriy V. Rogovchenko ${ }^{2}$ \\ ${ }^{1}$ Department of Mathematics, Linyi University, Linyi, Shandong 276005, China \\ ${ }^{2}$ Department of Mathematical Sciences, University of Agder, P.O. Box 422, 4604 Kristiansand, Norway
}

Correspondence should be addressed to Yuriy V. Rogovchenko; yuriy.rogovchenko@uia.no

Received 13 April 2014; Accepted 20 May 2014; Published 17 June 2014

Academic Editor: Qi-Ru Wang

Copyright (C) 2014 T. Li and Yu. V. Rogovchenko. This is an open access article distributed under the Creative Commons Attribution License, which permits unrestricted use, distribution, and reproduction in any medium, provided the original work is properly cited.

We analyze the oscillatory behavior of solutions to a class of second-order nonlinear neutral delay differential equations. Our theorems improve a number of related results reported in the literature.

\section{Introduction}

In this paper, we study the oscillatory behavior of a class of second-order nonlinear neutral delay differential equations

$$
\left(r(t)\left|z^{\prime}(t)\right|^{\alpha-1} z^{\prime}(t)\right)^{\prime}+q(t) f(x(\sigma(t)))=0,
$$

where $t \in I:=\left[t_{0}, \infty\right), t_{0}>0, z(t):=x(t)+p(t) x(\tau(t))$, and $\alpha>0$ is a constant. We assume that the following conditions hold:

$\left(\mathrm{A}_{1}\right) r, p, q \in C(I, \mathbb{R}), r(t)>0, p(t) \geq 0, q(t) \geq 0$, and $q(t)$ is not identically zero for large $t$;

$\left(\mathrm{A}_{2}\right) f \in C(\mathbb{R}, \mathbb{R}), u f(u)>0$, for all $u \neq 0$, and there exists a positive constant $k$ such that

$$
\frac{f(u)}{|u|^{\alpha-1} u} \geq k, \quad \forall u \neq 0
$$

$\left(\mathrm{A}_{3}\right) \sigma \in C(I, \mathbb{R}), \sigma(t) \leq t$, and $\lim _{t \rightarrow \infty} \sigma(t)=\infty$;

$\left(\mathrm{A}_{4}\right) \tau \in C^{1}(I, \mathbb{R}), \tau(t) \leq t$, and $\lim _{t \rightarrow \infty} \tau(t)=\infty$;

$\left(\mathrm{A}_{5}\right) \tau^{\prime}(t) \geq \tau_{0}>0$ and $\tau \circ \sigma=\sigma \circ \tau$.

By a solution of (1) we mean a function $x \in$ $C\left(\left[T_{x}, \infty\right), \mathbb{R}\right), T_{x} \geq t_{0}$, such that $r\left|z^{\prime}\right|^{\alpha-1} z^{\prime} \in C^{1}\left(\left[T_{x}, \infty\right), \mathbb{R}\right)$ and $x$ satisfies (1) on $\left[T_{x}, \infty\right)$. We consider only those solutions of (1) which satisfy $\sup \{|x(t)|: t \geq T\}>0$, for all $T \geq T_{x}$, and assume that (1) possesses such solutions. As customary, we say that a solution of (1) is oscillatory if it has arbitrarily large zeros on the interval $\left[T_{x}, \infty\right)$; otherwise, it is called nonoscillatory. Equation (1) is termed oscillatory if all its solutions are oscillatory.

An increasing interest in oscillation of solutions to functional differential equations during the last few decades has been stimulated by applications arising in engineering and natural sciences; see Hale [1]. This resulted in publication of several monographs [2-5] and numerous research articles [620]; see also the references cited there. Prior to presenting our oscillation criteria, we briefly comment on a number of closely related results for (1) and its particular cases which motivated the present study. In the sequel, the following notation is frequently used:

$$
f_{+}(t):=\max \{0, f(t)\}, \quad Q(t):=\min \{q(t), q(\tau(t))\} .
$$

Grace and Lalli [10] studied a second-order nonlinear neutral delay differential equation

$$
\left(r(t)(x(t)+p(t) x(t-\tau))^{\prime}\right)^{\prime}+q(t) f(x(t-\sigma))=0
$$

under the assumptions that

$$
\begin{gathered}
0 \leq p(t)<1, \quad \frac{f(u)}{u} \geq k>0, \quad \forall u \neq 0, \\
\int_{t_{0}}^{\infty} r^{-1}(t) d t=\infty .
\end{gathered}
$$


They proved that (4) is oscillatory if there exists a function $\rho \in C^{1}(I,(0, \infty))$ such that

$$
\int_{t_{0}}^{\infty}\left[\rho(t) q(t)(1-p(t-\sigma))-\frac{\left(\rho^{\prime}(t)\right)^{2} r(t-\sigma)}{4 k \rho(t)}\right] d t=\infty .
$$

Hasanbulli and Rogovchenko [11] obtained several oscillation criteria for a nonlinear neutral differential equation

$$
\left(r(t)(x(t)+p(t) x(t-\tau))^{\prime}\right)^{\prime}+q(t) f(x(t), x(\sigma(t)))=0
$$

in the case where $0 \leq p(t)<1$. Ye and $\mathrm{Xu}[18$, Theorem 2.1] proved the following result for (1).

Theorem 1. Suppose that $0 \leq p(t)<1, \sigma \in C^{1}(I, \mathbb{R})$, and $\sigma^{\prime}(t)>0$. Assume also that conditions $\left(A_{1}\right)-\left(A_{4}\right)$ are satisfied and

$$
\int_{t_{0}}^{\infty} r^{-1 / \alpha}(t) d t=\infty
$$

If there exists a function $\rho \in C^{1}(I,(0, \infty))$ such that

$$
\begin{aligned}
\int_{t_{0}}^{\infty} & {\left[\rho(t) q(t)(1-p(\sigma(t)))^{\alpha}\right.} \\
& \left.-\frac{1}{k(\alpha+1)^{\alpha+1}} \frac{\left(\rho_{+}^{\prime}(t)\right)^{\alpha+1} r(\sigma(t))}{\left(\rho(t) \sigma^{\prime}(t)\right)^{\alpha}}\right] d t=\infty,
\end{aligned}
$$

then (1) is oscillatory.

In a special case $f(u):=|u|^{\alpha-1} u$, (1) reduces to a quasilinear neutral differential equation

$$
\left(r(t)\left|z^{\prime}(t)\right|^{\alpha-1} z^{\prime}(t)\right)^{\prime}+q(t)|x(\sigma(t))|^{\alpha-1} x(\sigma(t))=0 .
$$

Equation (10) was studied by Sun et al. [17] and Zhong et al. [20] who established the following results.

Theorem 2 (see [17, Theorem 3.4]). Suppose that $\alpha \geq 1$, $\sigma(t) \geq \tau(t)$, and $0 \leq p(t) \leq p_{0}<\infty$. Assume also that conditions $\left(A_{1}\right),\left(A_{3}\right)-\left(A_{5}\right)$, and (8) are satisfied. If there exists a function $\rho \in C^{1}(I,(0, \infty))$ such that

$$
\int_{t_{0}}^{\infty}\left[\frac{\rho(t) Q(t)}{2^{\alpha-1}}-\frac{1+\left(p_{0}^{\alpha} / \tau_{0}\right)}{(\alpha+1)^{\alpha+1}} \frac{\left(\rho_{+}^{\prime}(t)\right)^{\alpha+1} r(\tau(t))}{\left(\tau_{0} \rho(t)\right)^{\alpha}}\right] d t=\infty
$$

then (10) is oscillatory.

Theorem 3 (see [20, Theorem 3.1]). Assume that $r^{\prime}(t) \geq 0$, $\tau(t)=t-\tau \leq t, 0 \leq p(t)=p_{0}<\infty, p_{0} \neq 1, \sigma \in C^{1}(I, \mathbb{R})$, and $\sigma^{\prime}(t)>0$. Suppose also that conditions $\left(A_{1}\right),\left(A_{3}\right)$, and
(8) are satisfied. If there exist an $\varepsilon \in(0,1)$ and a function $\rho \in$ $C^{1}(I,(0, \infty))$ such that

$$
\begin{aligned}
& \int_{t_{0}}^{\infty}\left[\frac{(1-\varepsilon)^{\alpha}}{\left(1+p_{0}(1+\varepsilon)\right)^{\alpha}} \rho(t) q(t)\right. \\
& \left.-\frac{1}{(\alpha+1)^{\alpha+1}} \frac{\left(\rho_{+}^{\prime}(t)\right)^{\alpha+1} r(\sigma(t))}{\left(\rho(t) \sigma^{\prime}(t)\right)^{\alpha}}\right] d t=\infty,
\end{aligned}
$$

then (10) is oscillatory.

The purpose of this note is to refine Theorems $1-3$ in some cases. In what follows, all functional inequalities are assumed to hold for all $t$ large enough. Without loss of generality, we can deal only with positive solutions of (1).

\section{Main Results}

For a more compact presentation of conditions in our results, we use the notation

$$
R(l, t):=\left(\int_{l}^{\sigma(t)} r^{-1 / \alpha}(s) d s\right)\left(\int_{l}^{t} r^{-1 / \alpha}(s) d s\right)^{-1} .
$$

Theorem 4. Let $0<\alpha \leq 1$ and $0 \leq p(t) \leq p_{0}<\infty$. Assume also that conditions $\left(A_{1}\right)-\left(A_{5}\right)$ and $(8)$ are satisfied. If there exists a function $\rho \in C^{1}(I,(0, \infty))$ such that

$$
\begin{aligned}
\int_{t_{* *}}^{\infty} & {\left[\rho(t) Q(t) R^{\alpha}\left(t_{*}, t\right)\right.} \\
& \left.\quad-\frac{\left(\rho_{+}^{\prime}(t)\right)^{\alpha+1}}{k(\alpha+1)^{\alpha+1} \rho^{\alpha}(t)}\left(r(t)+\frac{p_{0}^{\alpha} r(\tau(t))}{\tau_{0}^{\alpha+1}}\right)\right] d t=\infty
\end{aligned}
$$

for all sufficiently large $t_{*}$ and for some $t_{* *} \geq t_{*} \geq t_{0}$, then (1) is oscillatory.

Proof. Let $x(t)$ be a nonoscillatory solution of (1); we assume that it is eventually positive. Then there exists a $t_{1} \geq t_{0}$ such that $x(t)>0, x(\tau(t))>0$, and $x(\sigma(t))>0$, for all $t \geq t_{1}$. It follows from (1) that

$$
\begin{array}{r}
\left(r(t)\left|z^{\prime}(t)\right|^{\alpha-1} z^{\prime}(t)\right)^{\prime} \leq-k q(t) x^{\alpha}(\sigma(t)) \leq 0, \\
\forall t \geq t_{1} .
\end{array}
$$

Using condition (8), we conclude that there exists a $t_{2} \geq t_{1}$ such that $z^{\prime}(t)>0$, for all $t \geq t_{2}$. Hence, for all $t \geq t_{2}$, inequality (15) reduces to

$$
\left(r(t)\left(z^{\prime}(t)\right)^{\alpha}\right)^{\prime} \leq-k q(t) x^{\alpha}(\sigma(t)) \leq 0,
$$

and there exists a $t_{3} \geq t_{2}$ such that, for all $t \geq t_{3}$,

$$
p_{0}^{\alpha} \frac{\left(r(\tau(t))\left(z^{\prime}(\tau(t))\right)^{\alpha}\right)^{\prime}}{\tau^{\prime}(t)} \leq-k p_{0}^{\alpha} q(\tau(t)) x^{\alpha}(\sigma(\tau(t))) .
$$


Using the assumption $\tau^{\prime}(t) \geq \tau_{0}>0$, we have, for all $t \geq t_{3}$,

$$
\frac{p_{0}^{\alpha}}{\tau_{0}}\left(r(\tau(t))\left(z^{\prime}(\tau(t))\right)^{\alpha}\right)^{\prime} \leq-k p_{0}^{\alpha} q(\tau(t)) x^{\alpha}(\sigma(\tau(t))) .
$$

Combining inequalities (16) and (18), using the condition $\tau \circ \sigma=\sigma \circ \tau$ and an auxiliary result due to Baculíková and Džurina [7, Lemma 2], we conclude that

$$
\begin{aligned}
& \left(r(t)\left(z^{\prime}(t)\right)^{\alpha}\right)^{\prime}+\frac{p_{0}^{\alpha}}{\tau_{0}}\left(r(\tau(t))\left(z^{\prime}(\tau(t))\right)^{\alpha}\right)^{\prime} \\
& \quad \leq-k\left[q(t) x^{\alpha}(\sigma(t))+p_{0}^{\alpha} q(\tau(t)) x^{\alpha}(\tau(\sigma(t)))\right] \\
& \quad \leq-k \min \{q(t), q(\tau(t))\}\left[x^{\alpha}(\sigma(t))+p_{0}^{\alpha} x^{\alpha}(\tau(\sigma(t)))\right] \\
& \quad \leq-k Q(t) z^{\alpha}(\sigma(t)),
\end{aligned}
$$

for all $t \geq t_{3}$. Define a new function $\omega(t)$ by

$$
\omega(t):=\rho(t) \frac{r(t)\left(z^{\prime}(t)\right)^{\alpha}}{z^{\alpha}(t)} .
$$

Then $\omega(t)>0$, for all $t \geq t_{3}$. Differentiation of (20) yields

$$
\begin{aligned}
\omega^{\prime}(t)= & \rho^{\prime}(t) \frac{r(t)\left(z^{\prime}(t)\right)^{\alpha}}{z^{\alpha}(t)}+\rho(t) \frac{\left(r(t)\left(z^{\prime}(t)\right)^{\alpha}\right)^{\prime}}{z^{\alpha}(t)} \\
& -\alpha \rho(t) \frac{r(t)\left(z^{\prime}(t)\right)^{\alpha+1}}{z^{\alpha+1}(t)} \leq \rho(t) \frac{\left(r(t)\left(z^{\prime}(t)\right)^{\alpha}\right)^{\prime}}{z^{\alpha}(t)} \\
& +\frac{\rho_{+}^{\prime}(t)}{\rho(t)} \omega(t)-\frac{\alpha}{(\rho(t) r(t))^{1 / \alpha}} \omega^{(\alpha+1) / \alpha}(t) .
\end{aligned}
$$

Let

$$
A:=\frac{\rho_{+}^{\prime}(t)}{\rho(t)}, \quad B:=\frac{\alpha}{(\rho(t) r(t))^{1 / \alpha}}, \quad u:=\omega(t) .
$$

Using the inequality

$$
A u-B u^{(\alpha+1) / \alpha} \leq \frac{\alpha^{\alpha}}{(\alpha+1)^{\alpha+1}} \frac{A^{\alpha+1}}{B^{\alpha}}, \quad B>0,
$$

we deduce from (21) that

$$
\omega^{\prime}(t) \leq \rho(t) \frac{\left(r(t)\left(z^{\prime}(t)\right)^{\alpha}\right)^{\prime}}{z^{\alpha}(t)}+\frac{1}{(\alpha+1)^{\alpha+1}} \frac{\left(\rho_{+}^{\prime}(t)\right)^{\alpha+1} r(t)}{\rho^{\alpha}(t)} .
$$

Define another function $\nu(t)$ by

$$
\nu(t):=\rho(t) \frac{r(\tau(t))\left(z^{\prime}(\tau(t))\right)^{\alpha}}{z^{\alpha}(\tau(t))} .
$$

Observe that $\nu(t)>0$, for all $t \geq t_{3}$. Differentiation of (25) yields

$$
\begin{aligned}
\nu^{\prime}(t)= & \rho^{\prime}(t) \frac{r(\tau(t))\left(z^{\prime}(\tau(t))\right)^{\alpha}}{z^{\alpha}(\tau(t))} \\
& +\rho(t) \frac{\left(r(\tau(t))\left(z^{\prime}(\tau(t))\right)^{\alpha}\right)^{\prime}}{z^{\alpha}(\tau(t))} \\
& -\alpha \rho(t) \frac{r(\tau(t))\left(z^{\prime}(\tau(t))\right)^{\alpha} z^{\prime}(\tau(t)) \tau^{\prime}(t)}{z^{\alpha+1}(\tau(t))} \\
\leq & \rho(t) \frac{\left(r(\tau(t))\left(z^{\prime}(\tau(t))\right)^{\alpha}\right)^{\prime}}{z^{\alpha}(\tau(t))} \\
& +\frac{\rho_{+}^{\prime}(t)}{\rho(t)} \nu(t)-\frac{\alpha \tau^{\prime}(t)}{(\rho(t) r(\tau(t)))^{1 / \alpha}} \nu^{(\alpha+1) / \alpha}(t) .
\end{aligned}
$$

Let

$$
A:=\frac{\rho_{+}^{\prime}(t)}{\rho(t)}, \quad B:=\frac{\alpha \tau^{\prime}(t)}{(\rho(t) r(\tau(t)))^{1 / \alpha}}, \quad u:=\nu(t) .
$$

Using the inequalities (23) and (26) along with the fact that $z^{\prime}(t)>0$, we have

$$
\begin{aligned}
v^{\prime}(t) \leq & \rho(t) \frac{\left(r(\tau(t))\left(z^{\prime}(\tau(t))\right)^{\alpha}\right)^{\prime}}{z^{\alpha}(t)} \\
& +\frac{1}{(\alpha+1)^{\alpha+1}} \frac{\left(\rho_{+}^{\prime}(t)\right)^{\alpha+1} r(\tau(t))}{\left(\rho(t) \tau^{\prime}(t)\right)^{\alpha}} .
\end{aligned}
$$

Combining (24) and (28) and using the inequality (19), we obtain

$$
\begin{aligned}
\omega^{\prime}(t) & +\frac{p_{0}^{\alpha}}{\tau_{0}} v^{\prime}(t) \\
\leq & \rho(t) \frac{\left(r(t)\left(z^{\prime}(t)\right)^{\alpha}\right)^{\prime}+\left(p_{0}^{\alpha} / \tau_{0}\right)\left(r(\tau(t))\left(z^{\prime}(\tau(t))\right)^{\alpha}\right)^{\prime}}{z^{\alpha}(t)} \\
& +\frac{\left(\rho_{+}^{\prime}(t)\right)^{\alpha+1}}{(\alpha+1)^{\alpha+1} \rho^{\alpha}(t)}\left(r(t)+\frac{p_{0}^{\alpha} r(\tau(t))}{\tau_{0}^{\alpha+1}}\right) \\
\leq & -k \rho(t) Q(t) \frac{z^{\alpha}(\sigma(t))}{z^{\alpha}(t)} \\
& +\frac{\left(\rho_{+}^{\prime}(t)\right)^{\alpha+1}}{(\alpha+1)^{\alpha+1} \rho^{\alpha}(t)}\left(r(t)+\frac{p_{0}^{\alpha} r(\tau(t))}{\tau_{0}^{\alpha+1}}\right) .
\end{aligned}
$$

Since $\left(r(t)\left(z^{\prime}(t)\right)^{\alpha}\right)^{\prime} \leq 0$, we have

$$
z(t) \geq r^{1 / \alpha}(t) z^{\prime}(t) \int_{t_{2}}^{t} r^{-1 / \alpha}(s) d s,
$$


and thus

$$
\left(\frac{z(t)}{\int_{t_{2}}^{t} r^{-1 / \alpha}(s) d s}\right)^{\prime} \leq 0
$$

Consequently,

$$
\frac{z^{\alpha}(\sigma(t))}{z^{\alpha}(t)} \geq R^{\alpha}\left(t_{2}, t\right)
$$

Substitution of (32) in (29) yields

$$
\begin{aligned}
\omega^{\prime}(t)+\frac{p_{0}^{\alpha}}{\tau_{0}} v^{\prime}(t) \leq & -k \rho(t) Q(t) R^{\alpha}\left(t_{2}, t\right) \\
& +\frac{\left(\rho_{+}^{\prime}(t)\right)^{\alpha+1}}{(\alpha+1)^{\alpha+1} \rho^{\alpha}(t)}\left(r(t)+\frac{p_{0}^{\alpha} r(\tau(t))}{\tau_{0}^{\alpha+1}}\right) .
\end{aligned}
$$

Integrating (33) from $t_{3}$ to $t$, we have

$$
\begin{aligned}
\int_{t_{3}}^{t} & {\left[\rho(s) Q(s) R^{\alpha}\left(t_{2}, s\right)\right.} \\
& \left.\quad-\frac{\left(\rho_{+}^{\prime}(s)\right)^{\alpha+1}}{k(\alpha+1)^{\alpha+1} \rho^{\alpha}(s)}\left(r(s)+\frac{p_{0}^{\alpha} r(\tau(s))}{\tau_{0}^{\alpha+1}}\right)\right] d s \\
\leq & \frac{\omega\left(t_{3}\right)}{k}+\frac{p_{0}^{\alpha}}{k \tau_{0}} v\left(t_{3}\right) .
\end{aligned}
$$

Passing in (34) to the limit as $t \rightarrow \infty$, we obtain contradiction with condition (14). Therefore, (1) is oscillatory.

Proceeding as in the proof of Theorem 4 and using another result by Baculíková and Džurina [7, Lemma 1], we obtain the following oscillation criterion for (1), for $\alpha \geq 1$.

Theorem 5. Assume that $\alpha \geq 1$ and $0 \leq p(t) \leq p_{0}<\infty$. Let conditions $\left(A_{1}\right)-\left(A_{5}\right)$ and $(8)$ be satisfied. If there exists a function $\rho \in C^{1}(I,(0, \infty))$ such that

$$
\begin{aligned}
\int_{t_{* *}}^{\infty} & {\left[2^{1-\alpha} \rho(t) Q(t) R^{\alpha}\left(t_{*}, t\right)\right.} \\
& \left.\quad-\frac{\left(\rho_{+}^{\prime}(t)\right)^{\alpha+1}}{k(\alpha+1)^{\alpha+1} \rho^{\alpha}(t)}\left(r(t)+\frac{p_{0}^{\alpha} r(\tau(t))}{\tau_{0}^{\alpha+1}}\right)\right] d t=\infty,
\end{aligned}
$$

for all sufficiently large $t_{*}$ and for some $t_{* *} \geq t_{*} \geq t_{0}$, then (1) is oscillatory.

\section{Examples and Discussion}

Example 1. For $t \geq 1$, consider a second-order neutral differential equation

$$
\left(x(t)+\frac{1}{3} x(t-2)\right)^{\prime \prime}+\frac{\gamma}{t^{2}} x(t)=0
$$

where $\gamma>0$ is a constant. We have $\alpha=1, r(t)=1, p(t)=$ $p_{0}=1 / 3, \tau(t)=t-2, q(t)=\gamma / t^{2}, \sigma(t)=t, f(u)=u$, and $k=1$. Choose $\rho(t)=t$ and denote the left hand side of (14) by $\psi\left(t_{* *}\right)$. Then

$$
\psi\left(t_{* *}\right)=\left(\gamma-\frac{1}{3}\right) \int_{t_{* *}}^{\infty} \frac{d t}{t}=\infty, \quad \text { provided that } \gamma>\frac{1}{3}
$$

Hence, (36) is oscillatory by Theorem 4 for any $\gamma>1 / 3$. On the other hand, an application of Theorem 1 yields oscillation of (36) for $\gamma>3 / 8$, whereas Theorem 3 implies that (36) is oscillatory if $\gamma>(4+\varepsilon) /(3(4-4 \varepsilon))$, for some $\varepsilon \in$ $(0,1)$. Therefore, we observe that our Theorem 4 improves Theorems 1 and 3.

Example 2. For $t \geq 1$, consider a second-order neutral differential equation

$$
\left(x(t)+\frac{1}{3} x\left(\frac{t}{3}\right)\right)^{\prime \prime}+\frac{\gamma}{t^{2}} x(t)=0,
$$

where $\gamma>0$ is a constant. We have $\alpha=1, r(t)=1, p(t)=$ $p_{0}=1 / 3, \tau(t)=t / 3, q(t)=\gamma / t^{2}, \sigma(t)=t, f(u)=u$, and $k=1$. Let $\rho(t)=t$ and let $\psi$ be defined as in Example 1. Then

$$
\psi\left(t_{* *}\right)=(\gamma-1) \int_{t_{* *}}^{\infty} \frac{d t}{t}=\infty
$$

provided that $\gamma>1$. Therefore, by Theorem 4, (38) is oscillatory for any $\gamma>1$, whereas an application of Theorem 2 yields oscillation of (38) for all $\gamma>3 / 2$. Hence, Theorem 4 improves Theorem 2 .

\section{Conflict of Interests}

The authors declare that there is no conflict of interests regarding the publication of this paper.

\section{Acknowledgment}

The research of the first author is supported by the AMEP of Linyi University, China.

\section{References}

[1] J. K. Hale, Theory of Functional Differential Equations, Springer, New York, NY, USA, 1977.

[2] R. P. Agarwal, M. Bohner, and W. T. Li, Nonoscillation and Oscillation: Theory for Functional Differential Equations, Marcel Dekker, New York, NY, USA, 2004.

[3] R. P. Agarwal, S. R. Grace, and D. O'Regan, Oscillation Theory for Difference and Functional Differential Equations, Kluwer Academic Publishers, Dordrecht, The Netherlands, 2000.

[4] L. Erbe, Q. Kong, and B. G. Zhang, Oscillation Theory for Functional Differential Equations, Marcel Dekker, New York, NY, USA, 1995.

[5] G. S. Ladde, V. Lakshmikantham, and B. G. Zhang, Oscillation Theory of Differential Equations with Deviating Arguments, Marcel Dekker, New York, NY, USA, 1987. 
[6] B. Baculíková and J. Džurina, "Oscillation theorems for second order neutral differential equations," Computers \& Mathematics with Applications, vol. 61, no. 1, pp. 94-99, 2011.

[7] B. Baculíková and J. Džurina, "Oscillation theorems for secondorder nonlinear neutral differential equations," Computers \& Mathematics with Applications, vol. 62, no. 12, pp. 4472-4478, 2011.

[8] B. Baculíková and J. Džurina, "Oscillation theorems for higher order neutral differential equations," Applied Mathematics and Computation, vol. 219, no. 8, pp. 3769-3778, 2012.

[9] B. Baculíková, J. Džurina, and T. Li, "Oscillation results for evenorder quasilinear neutral functional differential equations," Electronic Journal of Differential Equations, vol. 2011, pp. 1-9, 2011.

[10] S. R. Grace and B. S. Lalli, "Oscillation of nonlinear second order neutral delay differential equations," Radovi Matematicki, vol. 3, pp. 77-84, 1987.

[11] M. Hasanbulli and Yu. V. Rogovchenko, "Oscillation criteria for second order nonlinear neutral differential equations," Applied Mathematics and Computation, vol. 215, no. 12, pp. 4392-4399, 2010.

[12] T. Li, R. P. Agarwal, and M. Bohner, "Some oscillation results for second-order neutral differential equations," The Journal of the Indian Mathematical Society, vol. 79, no. 1-4, pp. 97-106, 2012.

[13] T. Li, R. P. Agarwal, and M. Bohner, "Some oscillation results for second-order neutral dynamic equations," Hacettepe Journal of Mathematics and Statistics, vol. 41, no. 5, pp. 715-721, 2012.

[14] T. Li, Z. Han, P. Zhao, and S. Sun, "Oscillation of even-order nonlinear neutral delay differential equations," Advances in Difference Equations, vol. 2010, pp. 1-9, 2010.

[15] T. Li and Yu. V. Rogovchenko, "Asymptotic behavior of higherorder quasilinear neutral differential equations," Abstract and Applied Analysis, vol. 2014, Article ID 395368, 11 pages, 2014.

[16] T. Li, Yu. V. Rogovchenko, and C. Zhang, "Oscillation of secondorder neutral differential equations," Funkcialaj Ekvacioj, vol. 56, no. 1, pp. 111-120, 2013.

[17] S. Sun, T. Li, Z. Han, and H. Li, "Oscillation theorems for second-order quasilinear neutral functional differential equations," Abstract and Applied Analysis, vol. 2012, Article ID 819342, 17 pages, 2012.

[18] L. Ye and Z. Xu, "Oscillation criteria for second order quasilinear neutral delay differential equations," Applied Mathematics and Computation, vol. 207, no. 2, pp. 388-396, 2009.

[19] C. Zhang, R. P. Agarwal, M. Bohner, and T. Li, "New oscillation results for second-order neutral delay dynamic equations," Advances in Difference Equations, vol. 2012, article 227, 2012.

[20] J. Zhong, Z. Ouyang, and S. Zou, "An oscillation theorem for a class of second-order forced neutral delay differential equations with mixed nonlinearities," Applied Mathematics Letters, vol. 24, no. 8, pp. 1449-1454, 2011. 


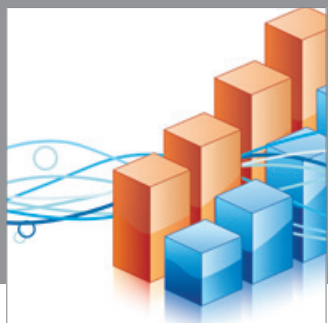

Advances in

Operations Research

mansans

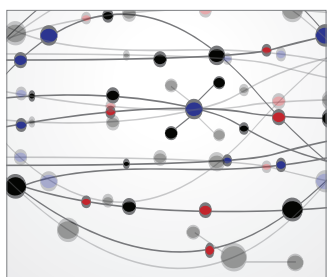

The Scientific World Journal
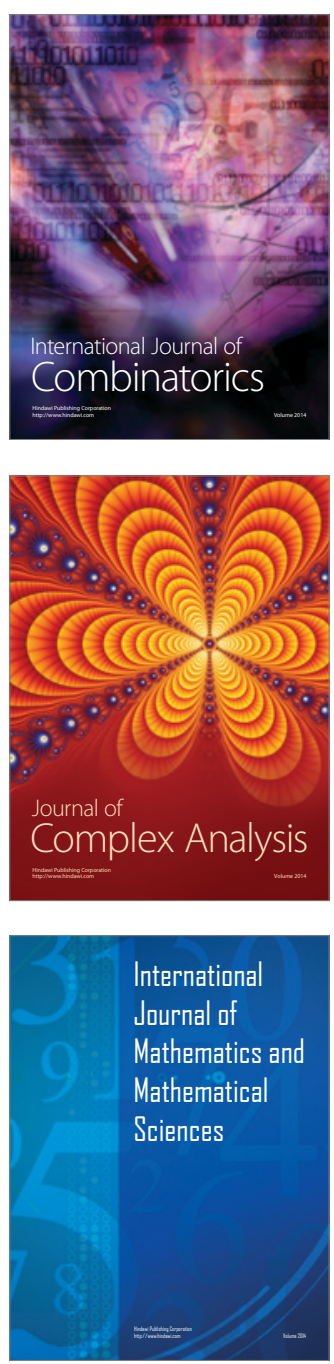
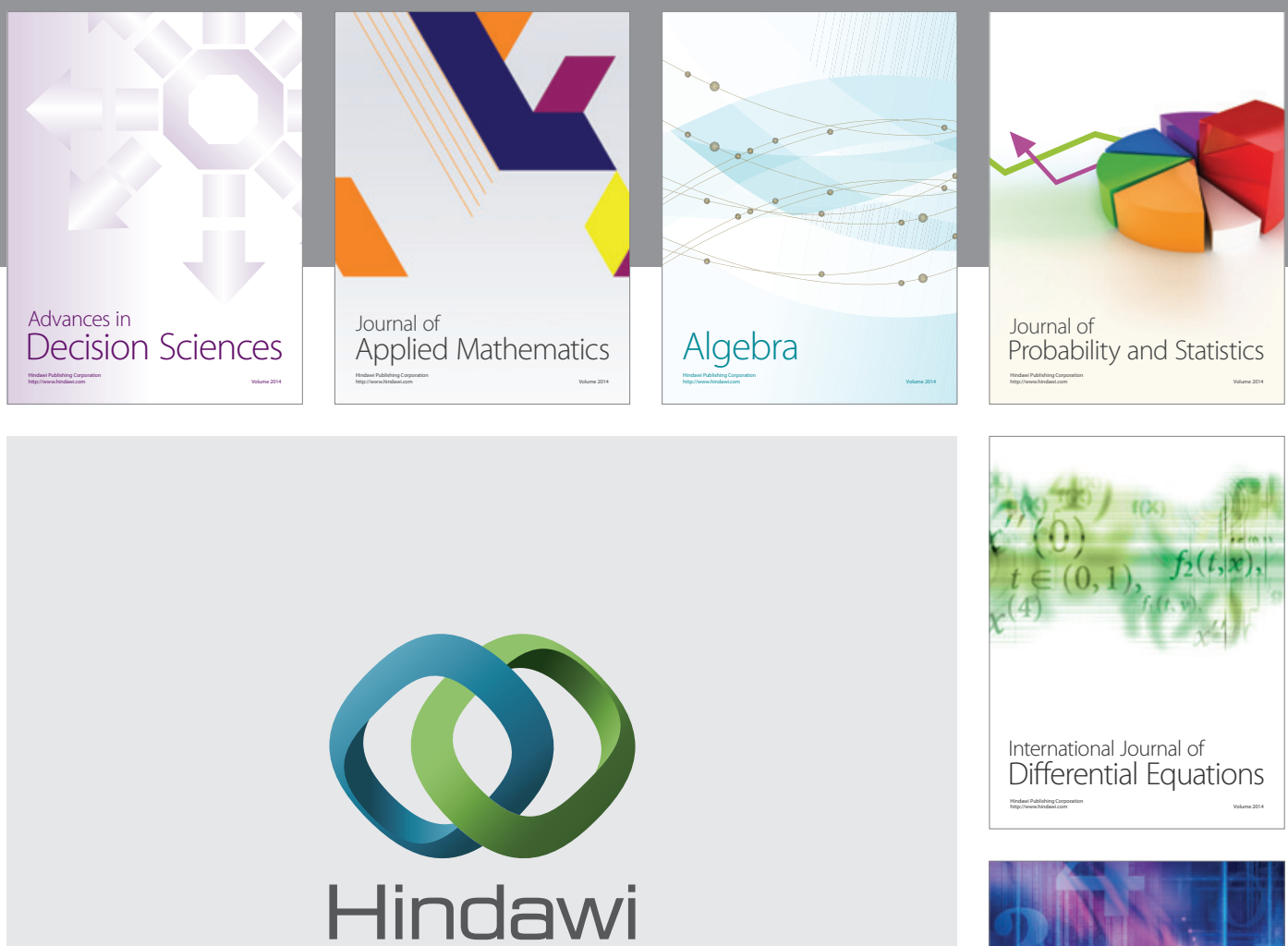

Submit your manuscripts at http://www.hindawi.com
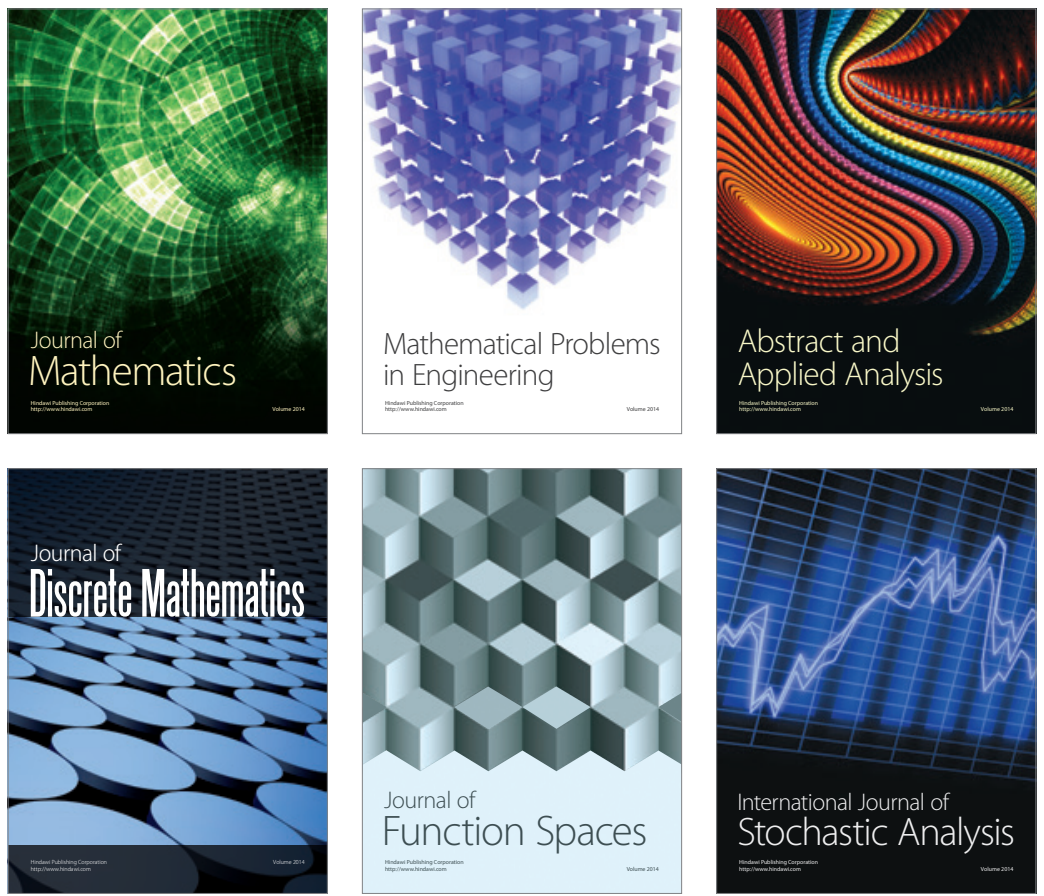

Journal of

Function Spaces

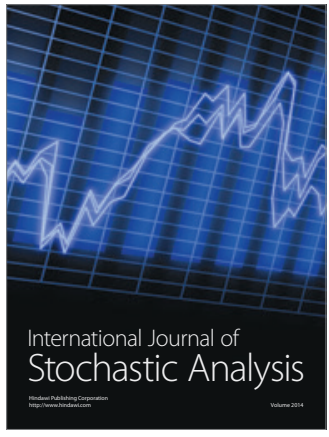

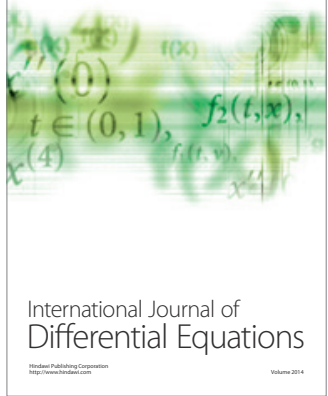
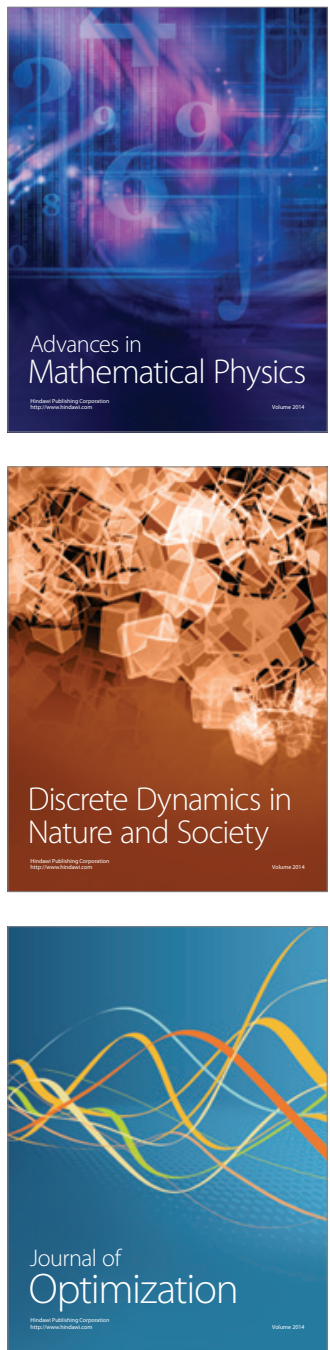